

\title{
Between a Rock and a Hard Place: Challenges in Enacting Procedural Justice in Resolving Sexual Harassment Complaints
}

\author{
Arosha S. Adikaram ${ }^{a}$, Pavithra Kailasapathy ${ }^{\mathrm{a}} \bowtie$ \\ ${ }^{a}$ Department of Human Resources Management, University of Colombo, Sri Lanka
}

\begin{abstract}
This paper aims to examine what impedes Human Resource Professionals' (HRPs) ability to enact procedural justice in resolving complaints of sexual harassment by identifying the challenges and difficulties HRPs encounter in practice. We conducted semi-structured, indepth interviews with 35 HRPs from 30 companies in Sri Lanka, employing a qualitative research approach. We found that HRPs face numerous challenges in enacting procedural justice. They struggle with competing demands to legally safeguard the company while also being fair to the parties concerned. We also found that complainants, other parties connected to the complaint, or observers can perceive HRPs as unfair even when they adhere to procedural justice principles. Understanding these challenges will help address some of the loopholes in complaint handling processes and highlight the need for interventions such as training to mitigate or eliminate the challenges HRPs face in taking fairer actions.
\end{abstract}

Keywords: Procedural Justice, Sexual Harassment Complaints, Human Resource Professionals, Challenges, Training

$\begin{array}{lll}\text { Received: } & \text { Accepted revised version: } & \text { Published: } \\ \text { 14 July 2021 } & \text { 20 November 2021 } & \text { 31 December 2021 }\end{array}$

Suggested citation: Adikaram, A. S. \& Kailasapathy, P. (2021). Between a rock and a hard place: challenges in enacting procedural justice in resolving sexual harassment complaints. Colombo Business Journal, 12(2), 103-127.

DOI: http://doi.org/10.4038/cbj.v12i2.84

(C2021 The Authors. This work is licensed under a Creative Commons Attribution 4.0 International License which permits unrestricted use, distribution, and reproduction in any medium, provided the original work is properly cited.

凶avithra@fmf.cmb.ac.lk (iD) https://orcid.org/0000-0002-8863-5822 


\section{Introduction}

Human Resource Professionals hold the key responsibility of preventing, combating, and handling sexual harassment in organisations. Amidst the numerous activities they engage in this regard, such as developing and implementing anti-sexual harassment policies, training and development, and providing support and protection to victims, investigating and resolving complaints of sexual harassment fairly and justly remain a primary responsibility (Goldberg et al., 2018). They need to take complaints of sexual harassment seriously, investigate those complaints without delay, and take disciplinary actions against perpetrators, which would contribute to zero-tolerance for sexual harassment in organisations (Goldberg et al., 2018; Hennekam \& Bennett, 2017). However, one of the most challenging and daunting tasks Human Resource Professionals (HRPs) have to engage in is handling complaints of sexual harassment fairly ${ }^{1}$ or justly while also being perceived as fair (Dorfman et al., 2000).

Sexual harassment is unwanted and unwelcome attention of sexual nature that is linked to power and gender (Chan \& Kleiner, 2000). Numerous legislations, guidelines, policies, procedures and research have specified or mandated how best to handle complaints of sexual harassment and have set forth clear criteria for safeguarding justice. In addition, established justice principles also stipulate criteria in ensuring fairness in making decisions and handling complaints and grievances in organisations (Leventhal, 1980). Among the many facets of justice (such as distributive justice, interactional justice and procedural justice) and stages of a complaint resolution (such as receiving a complaint, investigation, action), a just procedure is specifically important to provide a fair decision (Greenberg \& Tyler, 1987) regarding a complaint of sexual harassment. Research has shown that a just procedure is strongly connected to satisfaction, acceptance, adherence and future actions of the parties (Hollander-Blumoff, 2017) as well as job satisfaction, organisational commitment, performance and trust (Colquitt et al., 2001). As prior research indicates, employees will be reluctant to make formal complaints if they feel that complaining is futile (Freedman-Weiss et al., 2020).

On the contrary, employees will be more inclined to make formal complaints when they perceive the company's procedure to be just (Adams-Roy \& Barling, 1998; Bailey, 2020; Butler \& Chung-Yan, 2011). Such perception contributes to the prevention and reduction of sexual harassment occurrences. Further, research shows

\footnotetext{
${ }^{1}$ Fairness and justice and their derivatives are used interchangeably in this paper, similar to previous literature (e.g., Greenberg, 2011)
} 
that both the complainant and the accused would pursue litigation outside the company if they perceive procedural injustice (Neuser, 2005; Ruark, 2000; Smedley \& Rayment, 2018). If employees pursue litigation, courts will consider the company procedure's fairness in arriving at a judgment and hold the employer liable if procedural unfairness exists.

However, while numerous criteria and norms have been established to ensure procedural justice, there are many instances that decision-makers/HRPs fail to maintain justice or where they are seen as unfair (Eckert \& Steiner, 2018; Ruark, 2000; Taylor et al., 2019). Even though research has explored these instances of unfairness and ineffectiveness of complaint handling, why those occur have not been explored adequately. HRPs are often faulted for not following the due process to resolve sexual harassment complaints without really understanding why. There are also many instances where the HRPs are faulted for following the due process and guidelines. For example, following the due process involves collecting evidence and giving a fair hearing. However, collecting evidence and giving a fair hearing can lead to unavoidable delays in the process or the complaint being set aside due to lack of evidence, which can be seen as unfair.

Scholars have discussed different factors that can affect these perceptions of (in)justice (Elkins et al., 2008; Marrott, 2019) and why injustices occur, types of injustices, instances and inefficiencies in handling complaints of sexual harassment (e.g., Ruark, 2000). However, we could not find adequate exploration and explanation into the challenges that HRPs face not only in ensuring procedural justice and fairness in handling complaints of sexual harassment, but also in being perceived as fair and just. This is important because HRPs need not only to be fair but seen to be fair too. Justice and justice perception are like the foundations of people's behaviour and attitudes (Colquitt et al., 2015). We cannot effectively promote fairness, help HRPs act fairly or mitigate procedural injustice and be seen as being fair, without understanding these challenges. Hence, this paper explores the challenges HRPs face in upholding perceived justice and enacting procedural justice when handling complaints of sexual harassment. We explore these challenges by nesting the actions and inactions of HRPs within procedural justice principles under organisational justice literature.

\section{Literature Review}

In the literature review, first overview of organisational justice is provided with its three dimensions. Then, the relevance of organisational justice to sexual 
harassment is discussed bringing the two domains together. Finally, in understanding violations of justice (Colquitt et al., 2015) and agents' enactment of justice (Graso et al., 2020), we turn towards the challenges the HRPs face in handling complaints of sexual harassment.

Organisational justice describes the criteria and practices individuals would find fair and how individuals perceive fairness in organisations (Greenberg, 2011; Greenberg \& Tyler, 1987). Organisational justice enactment refers to the extent to which organisational agents and decision-makers (such as HRPs) adhere to or violate justice rules (Graso et al., 2020). Organisational justice, a multidimensional phenomenon, lists justice criteria under three broad dimensions: distributive, procedural and interactional justice. Throughout the last few decades, the understanding of organisational justice has matured with a plethora of research in the area providing answers to many questions on justice, such as what makes people perceive justice and what reasons motivate people to act justly or unjustly. However, as researchers highlight, several areas have not gained sufficient attention from scholars, such as violations of justice (Colquitt et al., 2015) and agents' enactment of justice (Graso et al., 2020).

Procedural justice has been identified as the most crucial among the different justice criteria (Tyler, 1988). Procedural justice is concerned with the fairness of the procedure followed in decision-making. While there are many criteria identified under procedural justice, the six criteria: a) consistency (consistency of the allocation and implementing of procedure across persons and over time) b) bias-suppression (subdual of individual biases and personal self-interests of decision-makers during the process; c) accuracy (correctness of the information used in the process); d) the correctability (existence of opportunities to change an unfair decision); e) representativeness (needs, values, and outlooks of all the parties affected by the process should be represented in the process); and f) ethicality (compatibility of the process with fundamental moral and ethical values of the perceiver) - are commonly identified as key to enacting procedural justice (Leventhal, 1980).

Harper et al. (2017) highlight that justice perceptions will be different for different parties and the criteria of justice can carry different levels of importance to the parties. Research has also explored the relative importance of procedural justice criteria, but conclusions have varied (e.g., Tyler, 1988). While the different viewpoints of the level of importance would be more prominent in terms of distributive justice (where a fair outcome perceived by a complainant can have more possibility of being seen as unfair by the perpetrator), there would be perceptual 
differences of what is a fair criterion under procedural justice as well. Scholars also highlight the interconnectivity of procedural justice with other justice dimensions especially distributive justice. For example, Harper et al. (2017) state that parties will accept and comply with an outcome, even in the absence of distributive justice, if the process followed to arrive at a decision is seen as fair. On the contrary, it is also suggested that even when the procedure has been just, individuals would see it as unjust if they disagree with the outcome (perceive distributive injustice). We will explore these facets of justice in our analysis and discussion.

Organisational justice theories have been used extensively in sexual harassment literature, mainly to explore how justice perceptions relate to the occurrence of sexual harassment (Krings \& Facchin, 2009; Rubino et al., 2018) or victim's reactions (Butler \& Chung-Yan, 2011). It has been well established that employees would be less likely to report sexual harassment incidents if they perceive their company to be handling such incidents unfairly (Butler \& Chung-Yan, 2011; McDonald, 2012). Further, they are less likely to pursue litigation against a company if they perceive that a company had been fair in handling their complaints (Neuser, 2005). Other parties, such as observers, will not encourage the victims to seek legal assistance if they perceive that the company had been fair in handling complaints of sexual harassment (Elkins et al., 2008). Thus, procedural justice has specifically been identified to impact the reporting of sexual harassment in organisations. If employees are sceptical about the company's response efficacy of filing a complaint, there would be higher rates of non-reported sexual harassment (McDonald, 2012).

Further, it was found that effectively managing the justice climate helps to deter sexual harassment (Adams-Roy \& Barling, 1998). Studies have explored what justice means to victims of sexual harassment and violence. In addition, studies have also identified different criteria and justice needs of victims when they make formal complaints to authorities (Clark, 2015; Heydon \& Powell, 2018). For example, in a study of victims-survivors of sexual violence, the following were found as criteria of justice by the victims: "acknowledgement and validation in responding to victimsurvivors, the desire for perpetrator responsibility and accountability, the role of retributive and punitive responses, and the relevance of a broader commitment to safety and prevention" (Clark, 2015, p. 19). However, we could not find studies that had used organisational justice theories to examine the (in)actions of HRPs in handling complaints of sexual harassment. Hence, how injustice takes place in handling complaints of sexual harassment appears to be an area that lacks detailed understanding. 
Identifying these procedural challenges HRPs face in handling complaints of sexual harassment will be significant empirically and theoretically. First, identifying the challenges will point towards areas that scholars and practitioners need to focus on for fairer handling of complaints of sexual harassment. Second, it will provide the basis for more specific and improved procedures and guidelines given to HRPs/other complaint handlers and complaint handling committees about promoting fairness in handling complaints by mitigating and eliminating the challenges.

From a theoretical perspective, our findings will add to the ever-expanding research on HRP's role in handling sexual harassment and the justice literature. Specifically, even though considerable literature highlights the importance of following the due process (Becton et al., 2017; Chan \& Kleiner, 2000), the issues HRPs face in following the due process have not been sufficiently discussed. Most importantly, by investigating the challenges HRPs face in making fair decisions, we address prior researchers' (e.g., Colquitt et al., 2015; Cropanzano et al., 2011; Graso et al., 2020) call for explorations on justice rule adherence and violations, how enacting justice can present challenges, and why and when decision-makers act (un)fairly.

\section{The Research Site (Sri Lanka) and Methodology}

Sri Lanka is one of the first countries in South Asia to introduce legislation prohibiting sexual harassment. The Penal Code of the country defines sexual harassment and the punishment as:

"whoever, by assault or use of criminal force, sexually harasses another person, or by the use of words or actions, causes sexual annoyance or harassment to such other person commits the offence of sexual harassment and shall on conviction be punished with imprisonment of either description for a term which may extend to five years or with fine or with both and may also be ordered to pay compensation of an amount determined by the court to the person in respect of whom the offence was committed for the injuries caused to such person" (Penal Code (Amendment) Act, No. 22 of 1995, - Section 345).

While this provision covers sexual harassment at workplaces, it was noted that only a handful of cases had gone to courts concerning sexual harassment at workplaces during the last few decades. Many cases do not get reported at the organisational level, let alone at the judicial level. Even when a case is reported to the police, it gets withdrawn later or settled outside the courts due to peer and social pressure. Moreover, in countries such as India, the process a company needs to follow 
is precisely detailed (The Sexual Harassment of Women at Workplace (Prevention, Prohibition and Redressal) Act, 2013). However, in the Sri Lankan legislation, such specific guidelines are not given. There is also no mandatory requirement for companies to have policies or procedures to combat and handle sexual harassment. Hence, many companies do not have any mechanism for handling sexual harassment. It is also interesting to note that even when specific policies and guidelines on sexual harassment exist in organisations, they are commonly linked to a disciplinary management process, indicating their unawareness of the complexity and uniqueness of sexual harassment.

With the absence of any specific legal requirement, the anti-sexual harassment policies and procedures would generally have different procedures and guidelines in handling complaints of sexual harassment. While some companies will have committees appointed to handle complaints of sexual harassment, others will place the responsibility on individuals such as HRPs or management, with steps such as investigation, show-cause and a domestic inquiry being specified. If sexual harassment is to be handled under the Penal Code as a criminal offence, the victims cannot take direct legal action against the perpetrator. They have to first complain to the police, and the police will take the matter forward after an initial investigation. The procedural challenges the HRPs face in handling complaints of sexual harassment thus needs to be understood within this legal and procedural context.

Employing a qualitative approach, we collected information regarding how HRPs handle complaints of sexual harassment they receive. Drawing from this main, broader study, we use the information gathered from 35 HRPs from 30 companies to understand their challenges in handling sexual harassment in their organisations. Information was gathered through in-person, semi-structured interviews using an interview guide. Each of the interviews was conducted by one of us. Interviews lasted on average an hour. We used the purposive sampling technique through personal contacts to select respondents. HRPs job positions ranged from very senior to juniorlevel management, with 20 of them being women.

The companies, all private, were from industries such as manufacturing, information technology, retail, service, finance and education. We had a mix of global, multinational and local organisations. Of the 30 organisations, 12 indicated that they had specific anti-sexual harassment policies. Three of the companies addressed sexual harassment under broader anti-harassment policies. Few others addressed sexual harassment through other policies such as anti-discrimination 
policies, disciplinary policies, human rights policy and code of conduct. Of the eight companies that did not address sexual harassment through any policies, two companies were developing anti-sexual harassment policies at the time of interviews.

Interview data were transcribed verbatim. We conducted thematic analysis through a process of coding and categorising. The six procedural justice criteria were used as the framework in collating and identifying the major themes from the codes and categories. The main themes represented the challenges the HRPs faced in enacting procedural justice. Accordingly, the challenges HRPs face in enacting procedural justice were captured through five core themes, namely, 1) upholding accuracy without (proper) evidence, 2) allowing representation without being unfair, 3) ensuring justice with inexpert committees, 4) maintaining confidentiality and protecting the victims, and 5) suppressing biases in the face of interventions from other parties. These themes flow from the procedural justice criteria and justice theory in general.

\section{Findings}

We use the procedural justice dimensions discussed under organisational justice literature as the framework to organise our findings. Accordingly, we identified that enacting procedural justice is not an easy task for the HRPs interviewed, especially when facing many challenges. The findings indicated five main challenges the HRPs encounter that we identified make it difficult and disconcerting for them to enact (procedural) justice.

\section{Upholding Accuracy without (Proper) Evidence}

In ensuring procedural justice is served to the parties concerned, decisions should be based on accurate information (Leventhal, 1980). Accurate information would be gathered through evidence collected during the investigation. The importance of accurate information or evidence is highlighted in sexual harassment policies and guidelines of companies and the country's general law and principles. For example, natural justice and due process principles state that facts must be established adequately to take action against sexual harassment. However, finding evidence was a main challenge for the HRPs, given the very nature of sexual harassment.

On the one hand, sexual harassment generally occurs in isolation cloaked in privacy (Elkins et al., 2008) and hence sufficient evidence might not always be available. In such instances, the complaint will be based on uncorroborated hearsay 
evidence, one person's word against the other without evidence to prove or disprove the complaint. On the other hand, due to unawareness, the victim might not collect evidence systematically. When sufficient evidence is not available, HRPs find it challenging to follow due process and resolve the complaint, as action without evidence will be unfair. However, HRPs not taking up a complaint or not taking action against the alleged perpetrator due to lack of evidence can be perceived as unjust by the victim and observers. For example, as HRP5 stated,

So, what happened was the inquiry ended by saying there was no evidence.... and we communicated to the victim that there is no strict evidence on this. She was not happy...because it's like he said, she said, that's all that happens.

Sometimes, the HRPs might know that sexual harassment had taken place, even without evidence, yet cannot help the victim due to legal and procedural restrictions on the action without evidence. If HRPs take action against the accused without evidence, the accused can retaliate legally on grounds of injustice or discrimination where the company will be at a disadvantage as actions against the perpetrator have been taken without accurate information. Such circumstances inevitably place the HRPs in a trying position to protect the company against litigation or protect the complainant's interest and other possible future victims.

There are also instances where even when specific evidence is available, the complainant does not present the evidence correctly, clearly, and timely due to reasons such as fear, embarrassment, unawareness or their emotional status as explained by HRP19:

Victims would not give proper evidence. Sometimes it might be a photograph, sexual harassment or might be a text message and they [complainants] are reluctant to show it.

Another reason for the reluctance of complainants is the fear of retaliation when the perpetrator is a senior official in the company, irrespective of the assurance of non-retaliation by the HRPs. An additional critical reason can be the deeply engrained cultural strictures and norms, that lead to issues relating to sexual harassment being treated with censure and distaste. Women are often blamed for sexual harassment and scorned for complaining and talking about sexual harassment. Further, suppose the evidence would contain information that would harm the complainants' image, such as videos, pictures or recordings indicating the sexuality of the complainant or indicating the reception of sexual advances of the alleged perpetrator. In that case, they might be further reluctant to either present the evidence or provide an accurate picture of the incident. In such situations, getting accurate information can be a 
challenge for HRPs. As HRP5 and a few other HRPs stated, complainants are also very emotional and vague when they come to HRP with their experiences, making it difficult for the HRP to understand and ascertain what happened. As HRP29 stated, Sometimes, they get scared to reveal the information. They say that something like this happened but wouldn't give the details properly. They get scared.... Sometimes, there can be more serious incidents than the one that was told to us. But they won't tell due to fear.... Some people, impulsively come and tell as soon as the incident happens...but later due to fear they change the story...Sometimes when we try to gather evidence and talk to people they say, 'miss, our jobs will be affected therefore we cannot tell you anything'.

According to HRPs, even the witnesses can be reluctant to give evidence due to the cumbersome process of participating in the investigation and the domestic inquiry and leading to labour tribunal cases. Besides, witnesses might also be reluctant to get involved in a complaint due to fear of reprisal from the perpetrator or their reluctance to get involved in a controversial issue such as sexual harassment - a taboo. As HRP6 stated,

Some people [witnesses], at the beginning might say I will give evidence and after that... when they hear of the process involved, they say 'no, no, no I can't give evidence'.

HRPs also stated instances where these difficulties in gathering evidence had led to delays in the process resulting in unrest among the employees who had perceived biases and injustice in the actions of the HRPs. HRP30 stated that a delay in handling a complaint of sexual harassment led to unrest among the other workers who demanded immediate action against the accused, assuming that the HRP intentionally delayed the process as she wanted to protect the alleged perpetrator.

\section{Allowing Representation without being Unfair}

Under the representation criterion, procedural justice highlights the importance of giving voice to the parties involved in decision-making. Further, it has been identified that employees may feel that they have been treated with procedural fairness when they feel that they have had a voice and control in the decision-making process and that they have been heard (Rubino et al., 2018).

However, in certain instances, granting employees' voice and control over the complaints of sexual harassment can pose many challenges to HRPs and impede their justice enactment. There were instances where the HRPs stated that the complainants had not wanted formal action to be taken regarding their complaint yet still wanted 
the harassment to stop without any action being taken against the alleged perpetrators or the alleged perpetrator being informed of the complaint against him. As HRP13 stated,

"This particular driver who did this is my husband's best friend. So, I don't want him to lose his job". So then how do you manage that? So, then the committee ...would have asked her what do you want? What do you expect us to do? Now you are telling us not to do anything to the guy, at the same time you are saying he harassed you. So, finally she decided to let it go because of her personal relationship with the husband.

HRP20 stated how culture affects complainants:

Ifeel like in these companies they have a culture...let's say even if somebody is doing something wrong, I feel they don't want to really basically do something for that person...because they don't see a kind of a bigger impact you know they have this Oh my gosh you know if that person loses his job, you know this is going to impact the family so I think people are ok to compromise you know thinking about the other person.

While maintaining justice and acting ethically, HRPs will be required to abide by these complainants' requests. However, without formal action being taken, the HRPs can do very little to resolve the issue. Moreover, this will place the HRP in an ethically compromising situation, where they cannot do much. However, HRPs know without formal action, they cannot ensure that the harassment would stop for the complainant and others like her.

\section{Ensuring Justice with Inexpert Committees}

Committees have been identified as more effective in carrying out investigations or making decisions regarding complaints of sexual harassment. They lead to neutrality, lesser biases and unfairness, than individuals handling the complaints (Reese \& Lindenberg, 2004). However, as the HRPs indicated, some organisations (mostly large scale or conglomerates) had committees of varying make-up appointed to handle complaints of sexual harassment. The responsibilities of these committees also differed. For example, in one MNC, the committee only receives the complaints, while in another company, the committee receives the complaint and carries out the inquiry process too. In a group of companies, the committee's primary responsibility was to decide the action to be taken based on the facts of the inquiry/investigation. Within this context, while the committees did get involved in resolving complaints of sexual harassment, the HRPs also played vital roles. Generally, they had the primary responsibility for handling the complaint. For example, when the committee's responsibility was to judge or take action based on the investigation, the HRP had to 
carry out the investigation. Similarly, when the committees only receive the complaints, the HRPs had to carry out the rest of the process, such as investigating and taking action.

HRPs interviewed also indicated another challenge they face when dealing with committees in handling complaints of sexual harassment. According to the HRPs, most of the committee members were not trained or sensitised about sexual harassment. They hence lacked a proper understanding of the uniqueness, nature, nuances and seriousness of sexual harassment. The organisations have been mainly concerned about having a legal representative and persons of higher positions in the committees and were rarely concerned about the committee members' knowledge about sexual harassment. Only HRP4 stated training committee members and empowering them on sexual harassment among the companies that had committees. Hence, when the committee members lack this sensitisation and understanding of the issue, they tend to treat complaints of sexual harassment like any other disciplinary issue leading to unfair decisions being taken.

In addition, many of these committee members also lack an understanding of conducting an inquiry or investigation. Hence, when part of the committee's responsibility is to investigate, they have failed to follow due process. This failure can result in biases, inconsistency, and inaccuracy in the committees' decisions and place the company at a disadvantageous position in front of the law. On the contrary, there were also committees consisting of company lawyers. While these lawyers would be knowledgeable about due process and conducting an investigation, according to the HRPs, they are excessively legal conscious and prioritise protecting the company from litigation. They would follow or insist on following the due process without considering the sensitive nature of the issue or the nuances and unique nature of the complaints of sexual harassment and the parties' different needs. Hence, the committee's complaint handling can be still seen as unfair even when they have followed the due process.

As the party holding the primary responsibility of handling complaints of sexual harassment, HRPs have been helpless in many of these instances, especially when the HRPs lack the power and experience to intervene or advice these committees that generally consist of higher officials. For example, HRP22 stated being relatively new to the company, she was unable to convince the members of the committee (who were from other disciplines and were more experienced and senior in the company) that looked into a sexual harassment complaint to follow due process when taking decision. 


\section{Maintaining Confidentiality and Protecting the Victims}

Maintaining confidentiality and protecting the parties from any retaliation are key criteria in an effective and fair complaint handling process (Becton et al., 2017). However, this is not always easy for the HRPs to ensure (Dyer \& Hurd, 2021). Confidentiality is essential to protect the victim and the accused (Ruark, 2000). Failure to maintain confidentiality can lead to various negative consequences, especially for the complainant.

HRPs found ensuring confidentiality to be a significant challenge for enacting justice. While HRPs attempt to ensure the confidentiality of the complaint and the complainant, they also have to collect information and evidence, which will involve interviewing different parties such as the complainant, witnesses and the accused. This step can unwittingly breach confidentiality. As HRP19 stated;

It takes a long time, maybe three four hours, to obtain the explanations [from the complainant], as we have to write, record and all that...so once the other Team members get to know that this girl is not in the work premises for three four hours, then they wonder and investigate as to why... she went to HR.

The HRPs are thus caught in a double bind between enacting justice through collecting information and protecting confidentiality. Even when HRPs have taken all the measures to ensure confidentiality, the incident might become known to others due to no fault of the HRPs, but other reasons. While there are specific strategies some HRPs employ to ensure confidentiality, such as conducting the interviews with the parties involved outside the office, this is not always possible and would not always ensure confidentiality within the collectivist culture. This is because employees are 'other-oriented' (Hofstede, 2001) and are concerned about what other group members are engaged in and involved in. For example, as HRM30;

But at the worker level, they talk about these [what is happening with other employees, about their behaviour, etc.]. So, from that perspective, it's difficult to maintain confidentiality. They talk among themselves.

There are also organisational grapevine and informal communication channels which can thwart HRPs efforts at confidentiality. In such instances where confidentiality has been compromised, the complainants (and other parties involved in the complaint) might misperceive the HRPs' role and blame the HRPs and the complaint handling process for not ensuring confidentiality. On the contrary, some HRPs believed that assuring confidentiality can sometimes be detrimental. It would not provide the 'warning' to other perpetrators to deter them from such behaviour as the complaint is handled confidentially. As HRP13 stated; 
but it always has the negative side because they don't know that management has taken action. If they know that four cases came and all four we solved the problem, that gives them courage ok I'm the fifth victim and I also can go up.

HRPs also stated that ensuring confidentiality can lead to them being seen as unfair as others would not know why a specific action was taken against certain employees (perpetrators). For example, HRP13 stated;

I know I'm doing the right thing but the outside world doesn't know the entire picture so then they have a perception that I have not been fair...that I am heartless.

HRPs also found it challenging to protect the complainants during the complaint process and once the complaint process comes to an end. HRPs are responsible for protecting the complainants from any retaliation by the alleged perpetrator and others such as colleagues or trade unions who support the alleged perpetrator. Simultaneously, the HRPs will also have to protect the complainant from other harmful acts such as rumours and gossip, which can be quite common in organisations. As HRP5 stated;

You still have to deal with whoever remains in the organisation. Say you terminate one party, the other party remains then for a while. There is a lot of damage controlling to do around that so it's a lot of investment, emotional and time investment on that.

HRP20 explains,

The main challenge is to really provide the right environment for the victim. Let's say person comes to us right and then we investigate, we take actions but at the same time...what happens if after removing that particular harasser from the system...there are a lot of other people to harass this person [the complainant] and also especially females...rather than protecting and supporting the person, what they [others] are trying to do is as much as possible put that person [further] down.

However, whether the HRPs can unequivocally ensure protection from retaliation, others' actions and rumours are questionable. While policies and procedures and training and awareness will help mitigate this issue to a certain extent, the issue can continue posing a challenge to the HRPs.

\section{Suppressing Biases in the Face of Interventions from Other Parties}

Many parties get involved during a complaint of sexual harassment, and these involvements can inevitably affect the effectiveness and justice of complaint handling (Kulik et al., 1997). As the study participants indicated, various actions of the top 
management, higher officials, trade unions and family members of the parties have unreasonably interfered with the enactment of justice.

\section{Influences from Higher Authorities}

HRPs have had to face and overcome numerous influences and threats from the company's higher officials, who can be the alleged perpetrator or those who support and protect the alleged perpetrator. HRPs stated that they had been pressured to disregard the case, not take it forward or not take serious action by these higher officials. For example, HRP6 said,

Sometimes they try to use their influence and power... "what the hell are you asking me to come for an inquiry?"...It's been very tough and very challenging for me and in fact I have received threats that I will be kicked out if you do this inquiry.

In few instances, the HRPs career has been threatened, obviously putting unnecessary strain on the HRPs, impacting the complaint's effective handling and enacting justice. In certain other instances, these higher officials have coerced or threatened the parties connected to the complaint, such as the complainant and the witnesses, influencing the investigation and the effective execution of the complaint handling process. For example, due to higher officials' threats or coercion, the witnesses will be reluctant to give evidence, or the complainant will try to withdraw the complaint. These influences and threats to be biased are additional and unwarranted pressure on the HRPs, affecting their bias suppression principle. HRPs have to withstand these pressures, sometimes amidst threats to their professions. Further, they also have to exert extra effort in convincing the parties, of the HRPs' need to be fair (to those who put direct pressure) or in convincing the parties to disregard these pressures of the higher officials (such as the witnesses). HRP25's statement explicates how it becomes difficult for the HRPs to enact justice due to the influence of the higher authorities;

Sometimes the CEO will have favourites and then they say the guy [the perpetrator] is a senior marketing manager who bring a lot of value to the company. Then they will let go of this. Because he is bringing money to the company. Or because of his connections. He [the perpetrator] will know somebody you know like the board of directors, or the CEO himself will be a character like that. Those are the challenges.

While in some instances, the higher officials will not threaten or influence the decisions of the HRPs. However, there were also instances where some of the HRPs

found it challenging to obtain the top management's support towards fair handling of complaints of sexual harassment. It was seen that sometimes the top management had not allowed the HRPs to follow the due process or had questioned or prevented HRPs 
from taking fair action against perpetrators. For example, HRP22 stated how she was unable to enact justice when she received few complaints of sexual harassment by a single person because the company's top management had not understood the severity of the issue and how to conduct a fair investigation. Hence, the Managing Director and the Chairman had not allowed her to follow due process and take action against the perpetrator, asking her not to act against the perpetrator.

\section{Influence from Trade Unions}

Few HRPs also stated how handling trade unions could pose a challenge for them. A few HRPs of our study narrated how trade unions had protected the perpetrators. While few HRPs stated that they have a good understanding with trade unions concerning sexual harassment incidents and that trade unions do not get involved in these instances, few others stated that trade unions could take the side of the accused if the accused is a member of a trade union, making it difficult for the HRPs to handle the case. In many trade unions, most of the members or the most powerful are the males. Hence, males being the most common harassers, the trade unions would protect the alleged perpetrators than the victims.

HRPs reported instances where the trade unions had opposed the action taken against the accused and demanded that the action be revoked. Both HRP9 and HRP17 stated how trade unions had exerted pressure on the HRPs when actions were taken against the accused. While the trade union of HRP17's company had not been aggressive, HRP9's trade union had engaged in a strike demanding that the accused be reinstated in his job. HRP17:

If the complaint is against someone in the Union, the Union will obviously get involved and they will try and like you know they will not have any logical reason and they will not be aggressive but they will just come on the sympathetic ground and say this man might leave the job so can you look at it in a way.

\section{HRP9:}

And they brought the whole place to a standstill and the Police took the view that 'this is a Police matter, you had no business to have sacked the accused. You should not have conducted your own investigation, you should have handed this over to the Police'.

This experience of HRP9 indicated not only the undue involvement of police in addition to the trade union but also the unawareness of the police, which can make enacting organisational justice a challenge for the HRPs. 
According to the HRPs, witnesses will be reluctant to give evidence when the union is involved. This reluctance is because there would be pressure and threats from the union, preventing them from giving evidence against the accused. Handling these numerous involvements and pressures from trade unions are especially difficult when the trade unions are more powerful.

Moreover, managing these different parties and being resilient in the many pressures put forward would be extra challenging when the HRPs are young and new or lack experience. In such instances, they would be pressured more and might not take a stand due to their lack of experience and lower positions in the organisations.

\section{Discussion}

Our study sought to understand the challenges HRPs face in enacting procedural justice in handling complaints of sexual harassment. HRPs enacting procedural justice and being perceived as just when handling complaints of sexual harassment are easier said than done. HRPs had to face numerous challenges in enacting justice. They also might not always have the discretion to act fairly or be constrained by various external factors and situations in enacting justice. As the findings above elucidate, these dilemmas and constraints, in the form of challenges, can occur when the HRPs are attempting to enact procedural justice, placing them 'between a rock and a hard place'.

In ensuring accuracy, the HRPs are mainly faced with the challenge of basing their decisions on evidence. However, as sexual harassment generally happens in isolation and secrecy, it is difficult to find evidence (Elkins et al., 2008). Furthermore, there are also many instances where the evidence and information would not be entirely or precisely presented due to reasons such as cultural norms and attitudes and fear of retaliation. In such situations, HRPs are forced to decide between truth or justice by either taking action against the alleged perpetrator even without evidence or accurate information based on the belief (collaborated by other factors such as the past behaviour and history of the parties) that the complainant is telling the truth or would act justly by setting aside the complaint due to lack of evidence. Hence, from a procedural justice perspective and to protect the company from any future legal action by the alleged perpetrator, the HRPs will be forced to either set aside the complaint or not take any action against the alleged perpetrator. However, this act of HRPs can be criticised as they would be more concerned with legal compliance and risk management (Charlesworth, 2002; Hogler et al., 2002), protecting the employers from liability rather than protecting or assisting the complainants (Dobbin \& Kelly, 
2007). At the same time, when sexual harassment has occurred, setting it aside due to lack of evidence will be against the general standards of fairness and morality, making it an act of injustice.

Further, as prior research indicates, people generally have low justice perceptions when sexual harassment allegations are denied by the investigators (Marrott, 2019). If the HRPs take the complaint forward and act against the alleged perpetrator without evidence or proper evidence, HRP's act is unjust or be seen as unjust (Leventhal, 1980). Moreover, wrongly accusing employees would be a significant drawback in enacting justice (Clark et al., 2018). Hence, there is an apparent dilemma that the HRPs face when there is a lack of evidence or when evidence is not timely or adequately presented. Scholars have identified these impediments that the decisionmakers face when they struggle to balance concepts such as truth, efficiency, accuracy, and justice (Clark et al., 2018). These situations where justice for both parties (complainant and the alleged perpetrator) cannot be simultaneously achieved would inevitably force HRPs to make value trade-offs between these two competing positions.

There are also other competing requirements and goals in handling complaints of sexual harassment that inevitably place HRPs in paradoxical situations. For example, it was seen that HRPs face difficulties in enacting justice with representation/giving voice to the complainant (Leventhal, 1980), another key criterion in ensuring procedural justice. As organisational justice research indicates, a decision will be fair and seen as fair when the parties are allowed to provide voice/input about the decision or provide higher control over particular decision-making processes (Frazier, 2000). The level and extent of this voice and control over the decision-making process would differ on the context and type of decision. It will also affect the level of acceptance of the decision and the decision's perceived fairness (Rubino et al., 2018). In resolving complaints of sexual harassment, the complainant is mainly given the right or control over the process, in that the HRPs will generally abide by the needs of the complainants in terms of what they need the HRPs to do (e.g., whether they want formal action taken or want to handle the issue informally). However, while such control given to the complainant on the process is very important on many counts, especially in influencing their perception of fairness, it can impede the HRPs' ability to enact justice. However, the HRPs might not be able to enact justice as they might not effectively stop harassment if they cannot conduct a formal investigation or even confront the alleged perpetrator to stop the harassment as the complainant does not want the matter handled formally. This requirement limits the HRPs' action to only 
be able to warn the alleged perpetrator indirectly or informally or take other informal minor actions, which might not be successful vis-à-vis more direct formal action. Further, such indirect and informal action can be seen as unjust by observers or might be seen as unfair by the alleged perpetrator him/herself as he/she is not aware of the complaint and had not been allowed to be heard or tell his/her side of the story. Therefore, in certain instances giving voice to the complainant can be at odds with what is best for the organisation and other employees and the complainant herself.

Posing another double-bind for the HRPs is the maintenance of confidentiality in handling complaints of sexual harassment. It is not always easy or possible. There are many instances in the complaint handling process that the confidentiality will be compromised, such as collecting evidence, informing the alleged perpetrator of the charges against him/her and requesting reasons for their behaviour. Hence, HRPs encounter a double-bind between their attempt to enact justice by collecting evidence, following the due process, and ensuring confidentiality. On the contrary, when confidentiality is maintained, the actions taken against the perpetrators can be seen as unfair as others would not be aware of the reasons for the actions.

Even though justice enactment is a shared responsibility (Graso et al., 2020) of the complainant, HRPs, and other stakeholders, it was seen how the actions and inactions of higher officials of the organisation and trade unions would also make it difficult for the HRPs to enact justice. When these pressures for HRPs to be biased exist, even when HRPs have suppressed the biases, others may see the HRPs and the procedure as biased. This perception of bias can be especially so if the outcome (e.g., actions taken against the perpetrator) is seen as unfavourable. As Elkins et al. (2008) affirm, when an outcome of a decision is seen favourably, the investigator would be seen as fair, irrespective of the bias suppression perception. Such perceptions lead to lesser reports of sexual harassment due to fear of retaliation (from the higher officials) and perceptions of unfairness (McDonald, 2012). Besides, the perception of bias will also lead to the parties perceiving even the other procedural justice criteria (such as voice and process control given to the parties) as not fairly carried out by the HRPs (even when they do) (McDonald, 2012).

While it is commonly accepted that committees can improve impartiality and reduce the biases that can come into the decision-making regarding a sexual harassment complaint (Reese \& Lindenberg, 2004), many drawbacks of these committees influenced the HRP's ability to enact justice. When HRPs have to deal with committees who are not sensitive to sexual harassment and not trained on 
handling sexual harassment, the process and the outcome will be seen as unfair. But of course, the HRPs have the primary responsibility to appoint the right people to these committees and provide them with the necessary training. However, the problems related to committees are a challenge to the HRPs in enacting justice.

\section{Theoretical and Practical Implications}

Our findings point towards some important theoretical and practical implications. From a practical perspective, first, these challenges that impede and refrain HRPs from acting fairly indicate the need to revisit the existing policies and procedures of handling complaints of sexual harassment. Moving beyond considering sexual harassment as another act of misconduct in the workplace, the unique and complex nature of sexual harassment needs to be given due consideration in developing and implanting policies and procedures related to sexual harassment. Management needs to give special attention to ensuring confidentiality and taking action without evidence by identifying the limitations in the current procedures and bringing about appropriate amendments to procedures that address these areas. It is also imperative that HRPs identify the importance of quality and accuracy of evidence rather than the amount of evidence in taking decisions. At the same time, in evaluating evidence, HRPs need not evaluate evidence as in a legal setting. There would be no need to prove a case beyond a reasonable doubt in organisations as in a legal setting and generally look at the balance of probability. This outlook will help navigate the issue of evidence.

Second, training, with emphasis on awareness creation and sensitisation to all employees on sexual harassment, special training to committee members on handling complaints of sexual harassment, and training on management responsibilities concerning sexual harassment, as well as training HRPs on handling sexual harassment fairly amidst many challenges they would face, is specifically important in addressing some of the challenges the HRPs face. At the same time, creating awareness about sexual harassment and biases among all the employees in organisations would also help mitigate the challenges (such as unnecessary pressure from different parties) to a certain extent. We mainly identify the importance of training stakeholders such as trade union officials to address sexual harassment. Further, improving the self-efficacy and confidence of HRPs to make just decisions is also important. Training, as well as top management support, is imperative in this regard.

From a theoretical perspective, the study's findings add to the justice literature and sexual harassment literature. Within the much-matured organisational justice 
discipline, an agent's role in organisational justice is mostly overlooked (Graso et al., 2020). Graso et al. (2020, p. 18) also said that the organisational justice research would benefit from a more detailed understanding of "how targets influence their agents' enactment of justice" and "how enacting justice can present challenges". Also, even though what will motivate decision-makers to act justly had been discussed (Graso et al., 2020), the challenges they face in enacting justice have not been adequately explored. Similarly, extant sexual harassment research has discussed how HRPs should handle complaints of sexual harassment effectively and justly and the challenges and issues HRPs face in handling harassment and bullying (see Fox \& Cowan, 2015). However, there is a vacuum in scholarly understanding of specific challenges HRPs face in handling complaints of sexual harassment justly. In other words, what helps or impedes their enactment of justice has not been explored sufficiently. Hence, by exploring and explaining the specific challenges and impediments the HRPs face in handling complaints of sexual harassment, we attempted to bridge these knowledge gaps.

\section{Limitations}

First, we interviewed HRPs only, which can weaken the study's trustworthiness to some extent. Triangulating this information can increase the trustworthiness of the study. Second, as the information shared by the HRPs were retrospective accounts of their experiences in handling complaints of sexual harassment, subsequent events and incidents might have affected their recollections. While these are common limitations in qualitative research, they would inevitably affect our understanding of the challenges in justice enactment by HRPs. The challenges that HRPs face when handling complaints of sexual harassment are not all from justice perspective. We have not addressed non-justice challenges.

\section{Conclusion}

In order for justice to be served when handling complaints of sexual harassment, HRPs need to be just and be perceived as being fair. As justice perceptions are often in the eyes of the beholder (Colquitt et al., 2015), HRPs might not be seen as fair in handling complaints of sexual harassment by all stakeholders. We see the HRPs' struggle between ethical and legal obligations amidst various challenges, some of which are inherent internal conflicts within the justice criteria. Hence, while we need to understand the many struggles and challenges HRPs face in enacting procedural justice in resolving complaints of sexual harassment, we also need to find ways and means to mitigate or eliminate these challenges. At the same time, HRPs need to 
balance the competing demands made on them and engage in the fairest possible action as some of these challenges will be difficult to mitigate or eliminate. Nevertheless, it is important that HRPs and organisations overcome these challenges so that complaints of sexual harassment can be handled fairly.

\section{Declaration of Conflicting Interests}

The authors declared no potential conflicts of interest with respect to the research, authorship, and publication of this article.

\section{Acknowledgement}

The authors would like to thank the two anonymous reviewers for their constructive comments to revise the paper.

\section{References}

Adams-Roy, J. \& Barling, J. (1998). Predicting the decision to confront or report sexual harassment. Journal of Organizational Behavior, 19(4), 329-336. https://www.jstor.org/stable/3100150

Bailey, E. (2020). Barriers to reporting sexual harassment: What encourages disclosure (Unpublished doctoral dissertation) University of Windsor, Canada.

Becton, J. B., Gilstrap, J. B., \& Forsyth, M. (2017). Preventing and correcting workplace harassment: Guidelines for employers. Business Horizons, 60(1), 101-111. https://doi.org/10.1016/j.bushor.2016.09.005

Butler, A. M., \& Chung-Yan, G. A. (2011). The influence of sexual harassment frequency and perceptions of organizational justice on victim responses to sexual harassment. European Journal of Work and Organizational Psychology, 20(6), 729-754. https://doi.org/10.1080/1359432X.2010.507351

Chan, A., \& Kleiner, B. H. (2000). How to investigate discrimination and harassment complaints. Equal Opportunities International, 19(1), 19-25. https://doi.org/10.1108/02610150010786120

Charlesworth, S. (2002). Risky business: Managing sexual harassment at work. Griffith Law Review, 11(2), 353-376.

Clark, H. (2015). A fair way to go: Justice for victim-survivors of sexual violence. In A. Powell, N. Henry, \& A. Flynn (Eds.), Rape justice: Beyond the criminal law (pp. 18-35). Palgrave Macmillan

Clark, S. E., Moreland, M. B., \& Larson, R. P. (2018). Legitimacy, procedural justice, accuracy, and eyewitness identification. UC Irvine Law Review, 8(1), 41-84. https://scholarship.law.uci.edu/ucilr/vol8/iss1/5/ 
Colquitt, J. A., Conlon, D. E., Wesson, M. J., Porter, C. O., \& Ng, K. Y. (2001). Justice at the millennium: A meta-analytic review of 25 years of organizational justice research. Journal of Applied Psychology, 86(3), 425-445. https://doi.org/10.1037/0021-9010.86.3.425

Colquitt, J. A., Long, D. M., Rodell, J. B., \& Halvorsen-Ganepola, M. D. K. (2015). Adding the "in" to justice: A qualitative and quantitative investigation of the differential effects of justice rule adherence and violation. Journal of Applied Psychology, 100(2), 278-297. https://doi.org/10.1037/a0038131

Cropanzano, R., Stein, J. H., \& Nadisic, J. (2011). Social justice and the experience of emotion, Routledge.

Dobbin, F. \& Kelly, E. L. (2007). How to stop harassment: professional construction of legal compliance in organizations. American Journal of Sociology, 112(4), 1203-1243. https://doi.org/10.1086/508788

Dorfman, P. W., Cobb, A. T., \& Cox, R. (2000). Investigations of sexual harassment allegations: Legal means fair-Or does it? Human Resource Management, 39(1), 33-49._https://doi.org/10.1002/(SICI)1099050X(200021)39:1<33::AID-HRM4>3.0.CO;2-4

Dyer, S. \& Hurd, F. (2021). Training the next generation HR practitioners: Reflecting on HRM student experiences of sexual harassment training. Hospitality \& Society, 11(1), 27-46. https://doi.org/10.1386/hosp_00027_1

Eckert, S. \& Steiner, L. (2018). Sexual harassment in media education. Communication, Culture and Critique, 11(3), 484-488. https://doi.org/10.1093/ccc/tcy017

Elkins, T. J., Phillips, J. S., \& Ward, S. G. (2008). Organizational sexual harassment investigations: Observers' perceptions of fairness. Journal of Managerial Issues, 20(1), 88-108. https://www.jstor.org/stable/40604596

Fox, S. \& Cowan, R. L. (2015). Revision of the workplace bullying checklist: The importance of human resource management's role in defining and addressing workplace bullying. Human Resource Management Journal, 25(1), 116-130. https://doi.org/10.1111/1748-8583.12049

Frazier, P. A. (2000). The role of attributions and perceived control in recovery from rape. Journal of Personal and Interpersonal Loss, 5(2-3), 203-225. https://doi.org/10.1080/10811440008409753

Freedman-Weiss, M. R., Chiu, A. S., Heller, D. R., Cutler, A. S., Longo, W. E., Ahuja, N., \& Yoo, P. S. (2020). Understanding the barriers to reporting sexual harassment in surgical training. Annals of Surgery, 271(4), 608-613. https://journals.lww.com/annalsofsurgery/Abstract/2020/04000/Understanding_ the_Barriers_to_Reporting_Sexual.3.aspx 
Goldberg, C. B., Rawski, S. L., \& Perry, E. L. (2018). The direct and indirect effects of organizational tolerance for sexual harassment on the effectiveness of sexual harassment investigation training for HR managers. Human Resource Development Quarterly, 30(1), 81-100. https://doi.org/10.1002/hrdq.21329

Graso, M., Camps, J., Strah, N., \& Brebels, L. (2020). Organizational justice enactment: An agent-focused review and path forward. Journal of Vocational Behavior, 116(Part B). https://doi.org/10.1016/j.jvb.2019.03.007

Greenberg, J. (2011). Organizational justice: The dynamics of fairness in the workplace. In S. Zedeck (Ed.), Handbook of industrial and organizational psychology (Vol. 3, pp. 271-327). APA Press.

Greenberg, J. \& Tyler, T. R. (1987). Why procedural justice in organizations? Social Justice Research, 1(2), 127-142. https://doi.org/10.1007/BF01048012 Harper, S., Maskaly, J., Kirkner, A., \& Lorenz, K. (2017). Enhancing title IX due process standards in campus sexual assault adjudication: Considering the roles of distributive, procedural, and restorative justice. Journal of School Violence, 16(3), 302-316. https://doi.org/10.1080/15388220.2017.1318578

Hennekam, S. \& Bennett, D. (2017). Sexual harassment in the creative industries: Tolerance, culture and the need for change. Gender, Work \& Organization, 24(4), 417-434. https://doi.org/10.1111/gwao.12176

Heydon, G., \& Powell, A. (2018). Written-response interview protocols: An innovative approach to confidential reporting and victim interviewing in sexual assault investigations. Policing and Society, 28(6), 631-646. https://doi.org/10.1080/10439463.2016.1187146

Hofstede, G. (2001). Culture's recent consequences: Using dimension scores in theory and research. International Journal of Cross Cultural Management, 1(1), 11-17. https://doi.org/10.1177/147059580111002

Hogler, R. L., Frame, J. H., \& Thornton, G. (2002). Workplace sexual harassment law: An empirical analysis of organizational justice and legal policy. Journal of Managerial Issues, 14(2), 234-250. https://www.jstor.org/stable/40604386

Hollander-Blumoff, R. (2017). Formation of procedural justice judgments in legal negotiation. Group Decision and Negotiation, 26(1), 19-43.

https://doi.org/10.1007/s10726-016-9498-2

Krings, F. \& Facchin, S. (2009). Organizational justice and men's likelihood to sexually harass: The moderating role of sexism and personality. Journal of Applied Psychology, 94(2), 501-510. https://doi.org/10.1037/a0013391

Kulik, C. T., Perry, E. L., \& Schmidtke, J. M. (1997). Responses to sexual harassment: The effect of perspective. Journal of Managerial Issues, 9(1), 3753. https://www.jstor.org/stable/40604128 
Leventhal, G. S. (1980). What should be done with equity theory? New approaches to the study of fairness in social relationship. In K. J. Gergen, M. S. Greenberg, \& R. H. Willis (Eds.), Social exchange: Advances in theory and research (pp. 27-55). Plenum.

Marrott, D. (2019). Sexual harassment, justice perceptions, and social identity: Cognition and group dynamics (Unpublished master's dissertation). California State University, San Bernardino.

McDonald, P. (2012). Workplace sexual harassment 30 years on: A review of the literature. International Journal of Management Reviews, 14(1), 1-17. https://doi.org/10.1111/j.1468-2370.2011.00300.x

Neuser, D. J. (2005). How to conduct effective internal investigations of workplace matters. Employee Relations Law Journal, 31(1), 67-89.

Penal Code (Amendment) Act, No. 22 of 1995, Section 345. https://www.lawnet.gov.lk/penal-code-amendment-5/

Reese, L. A. \& Lindenberg, K. E. (2004). Employee satisfaction with sexual harassment policies: The training connection. Public Personnel Management, 33(1), 99-119. https://doi.org/10.1177/009102600403300108

Ruark, K. S. (2000). Damned if you do, damned if you don't? Employers' challenges in conducting sexual harassment investigations. Georgia State University Law Review, 17(2), 575-604. https://readingroom.law.gsu.edu/gsulr/vol17/iss2/6/

Rubino, C., Avery, D. R., McKay, P. F., Moore, B. L., Wilson, D. C., Van Driel, M. S., Witt, L. A., \& McDonald, D. P. (2018). And justice for all: How organizational justice climate deters sexual harassment. Personnel Psychology, 71(4), 519-544. https://doi.org/10.1111/peps.12274 .

Smedley, D. \& Rayment, A. (2018). Time for change-HR's role in eradicating workplace sexual harassment. Strategic HR Review, 17(2), 85-90. https://doi.org/10.1108/SHR-01-2018-0004

Taylor, E. A., Jones, G. J., McCray, K., \& Hardin, R. (2019). Creating ethical decision makers: The influence of education on perceptions of sexual harassment and sexual assault. Sport Management Education Journal, 13(2), 73-82. https://doi.org/10.1123/smej.2019-0004

The Sexual Harassment of Women at Workplace (Prevention, Prohibition and Redressal) Act, 2013. https://legislative.gov.in/sites/default/files/A2013-14.pdf

Tyler, T. R. (1988). What is procedural justice? Criteria used by citizens to assess the fairness of legal procedures. Law \& Society Review, 22(1), 103-136. https://doi.org/10.2307/3053563 